\title{
MALDI-TOF MS as a method for rapid identification of Phytophthora de Bary, 1876
}

\author{
Matěj Božik ${ }^{\text {Corresp., } 1}$, Marcela Mrazkova ${ }^{2}$, Karolína Novotná $^{1}$, Marketa Hrabetova ${ }^{2}$, Petr Marsik ${ }^{1}$, Pavel Kloucek ${ }^{1}$, \\ Karel Cerny ${ }^{\text {Corresp. } 2}$ \\ ${ }^{1}$ Czech University of Life Sciences, Department of Food science, Prague, Czech Republic \\ 2 The Silva Tarouca Research Institute for Landscape and Ornamental Gardening, Kvetnove nam. 391, 25243 ,. Pruhonice, Czech Republic \\ Corresponding Authors: Matěj Božik, Karel Cerny \\ Email address: bozik@af.czu.cz, Karel.Cerny@vukoz.cz
}

The number of described species of the oomycete genus Phytophthora is growing rapidly, highlighting the need for low-cost, rapid tools for species identification. Here, a collection of 24 Phytophthora species (42 samples) from natural as well as anthropogenic habitats were genetically identified using the internal transcribed spacer (ITS) and cytochrome c oxidase subunit I (COI) regions. Because genetic identification is time consuming, we have created a complementary method based on by matrix-assisted laser desorption ionization-time of flight mass spectrometry (MALDI-TOF MS). Both methods were compared and hypothesis that the MALDI-TOF MS method can be a fast and reliable method for the identification of oomycetes was confirmed. Over 3500 mass spectra were acquired, manually reviewed for quality control, and consolidated into a single reference library using the Bruker MALDI Biotyper platform. Finally, a database containing 144 main spectra (MSPs) was created and published in repository. The method presented in this study will facilitate the use of MALDI-TOF MS as a complement to existing approaches for fast, reliable identification of Phytophthora isolates. 
1 MALDI-TOF MS as method for rapid identification of

2 Phytophthora de Bary, 1876

3

4

5

6

7

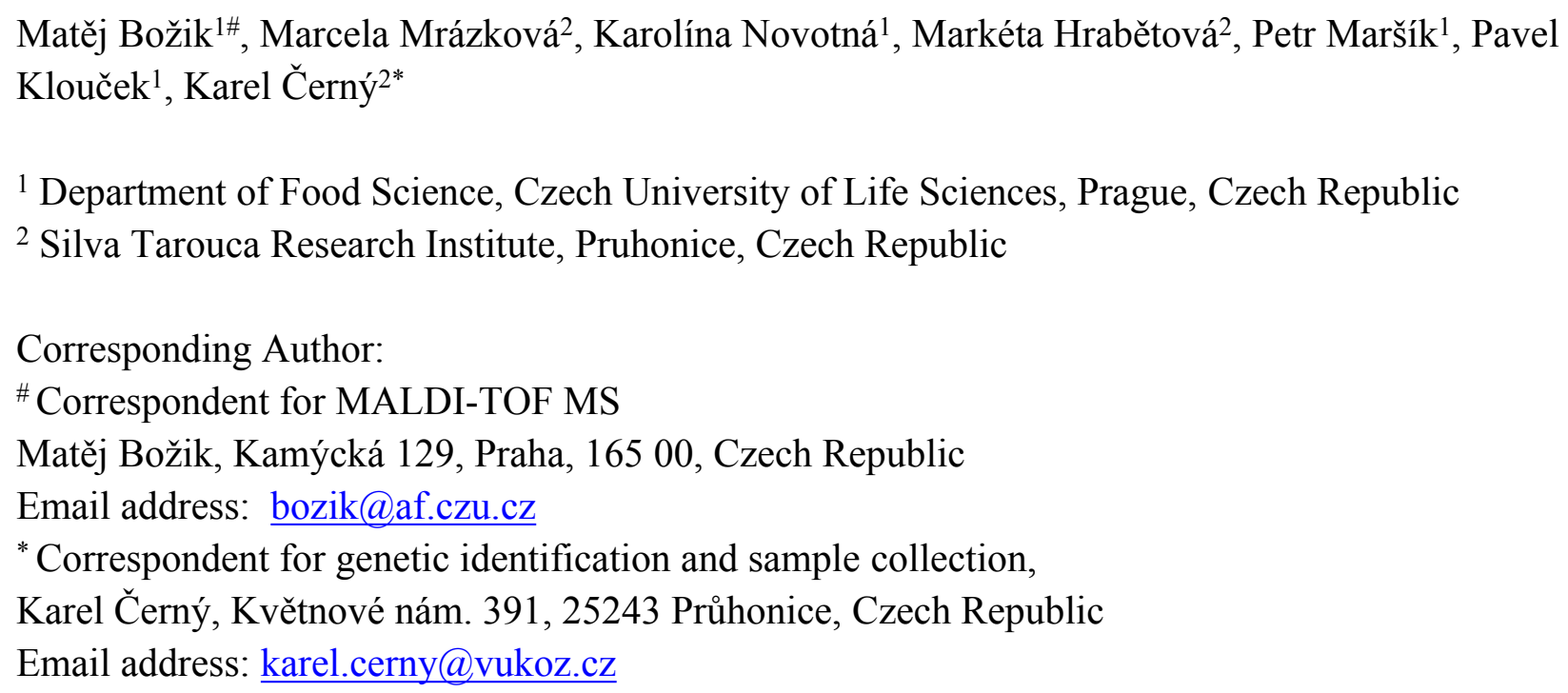

\section{Abstract}

The number of described species of the oomycete genus Phytophthora is growing rapidly, highlighting the need for low-cost, rapid tools for species identification. Here, a collection of 24 Phytophthora species (42 samples) from natural as well as anthropogenic habitats were genetically identified using the internal transcribed spacer (ITS) and cytochrome c oxidase subunit I (COI) regions. Because genetic identification is time consuming, we have created a complementary method based on by matrix-assisted laser desorption ionization-time of flight mass spectrometry (MALDI-TOF MS). Both methods were compared and hypothesis that the MALDI TOF method can be a fast and reliable method for the identification of oomycetes was confirmed. Over 3500 mass spectra were acquired, manually reviewed for quality control, and consolidated into a single reference library using the Bruker MALDI Biotyper platform. Finally, a database containing 144 main spectra (MSPs) was created and published in repository. The method presented in this study will facilitate the use of MALDI-TOF MS as a complement to existing approaches for fast, reliable identification of Phytophthora isolates.

\section{Introduction}

The oomycete genus Phytophthora was first established by de Bary in 1876 with the type species P. infestans, which causes potato blight and was the culprit in a series of famines in Europe (De Bary, 1876). Members of this genus are among the most cited pathogens worldwide and are associated with annual economic losses reaching billions of dollars (Erwin \& Ribeiro, 1996). Plant pathogens belonging to Phytophthora impact agriculture, horticulture, forestry, and natural ecosystems (Hansen, Reeser \& Sutton, 2012), and epidemics of the most destructive species, 
40 including $P$. alni, $P$. austrocedrae, $P$. cinnamomi, $P$. ramorum, and $P$. kernoviae, have occurred 41 in various parts of the world (Greslebin, Hansen \& Sutton, 2007). The number of described 42 Phytophthora species grew from 58 in 1996 (Erwin \& Ribeiro, 1996) to 313 in 2018 (H Ho, 43 2018), followed by a dramatic spike in recent years to an estimated total of 600 (Brasier, 2009). 44 New species have been split from old species as species complexes were resolved but are also 45 arising from the recent hybridization of existing species such as Phytophthora alni subsp. alni 46 (Husson et al., 2015; Mizeriene et al., 2020). Some of these new species have been described as causal agents of new diseases, while others have been discovered through the exploration of new habitats.

This explosion in diversity is also the result of applying new molecular tools to taxonomy (Hansen, Reeser \& Sutton, 2012). Traditionally, species descriptions were based on morphological characteristics, but phenotypic species identification is time-consuming and requires specialized scientific knowledge (Ruiz Gómez et al., 2019). Studies of soil fungal and oomycetous communities have benefitted from modern techniques like next-generation sequencing (NGS) (Hardham \& Blackman, 2018), pyrosequencing and second-generation techniques such as metabarcoding (Prigigallo et al., 2016) based on Illumina de novo sequencing. Although morphological characteristics still serve as the basis for the preliminary orientation and identification of Phytophthora species, various genetic methods are now routinely used when overlapping morphological features and intraspecific variability present a challenge for Phytophthora species identification (Martin et al., 2012).

In these techniques, species identification typically depends on sequencing of the internal transcribed spacer (ITS) region of ribosomal DNA (rDNA) (Cooke et al., 2000; Grünwald et al., 2011; Sandoval-Sierra, Martín \& Diéguez-Uribeondo, 2014; Jung et al., 2019). Online databases such as GenBank (www.ncbi.nlm.nih.gov) and EMBL (www.ebi.ac.uk) collect sequence data and allow species identification by BLAST based primarily on the coefficient of similarity of DNA and RNA sequences (Ristaino, 2012; H Ho, 2018). For the genus Phytophthora, the "Phytophthora Database" (www.phytophthoradb.org) provides information on morphological features, geographic distribution, and relevant references (Park et al., 2008). The advantage of the ITS region is that its sequence can readily be obtained, and the ITS sequences of many Phytophthora species are currently available in GenBank. However, a disadvantage of ITS sequences is that there are minimal or no differences between closely related species, such as $P$. rubi and P. fragariae (Martin et al., 2012), and intraspecific variation can blur the boundaries between some species. Additional genetic regions that are commonly used for species identification include the mitochondrial cytochrome c oxidase subunit genes (COX1 and COX2) (Martin \& Tooley, 2003; Kroon et al., 2004; Robideau et al., 2011), but the need to sequence additional regions further increases the cost, which is a limiting factor for identification based on DNA sequencing (Del Castillo-Múnera et al., 2013).

A potential alternative to sequencing is matrix-assisted laser desorption ionization-time of flight mass spectrometry (MALDI-TOF MS). MALDI-TOF MS is a fast and direct form of analysis that requires no chromatographic separation (Galeano Garcia et al., 2018). Recent studies have 
80

81

82

83

84

85

86

87

88

89

90

91

92

93

94

95

96

97

98

99

100

101

102

103

104

105

106

107

108

109

110

111

112

113

114

115

116

117

118

119

shown that MALDI biotyping is a fast and reliable method of species identification for mushrooms (Sugawara et al., 2016; El Karkouri et al., 2019), yeasts, molds (Rizzato et al., 2015; Drissner \& Freimoser, 2017), mycorrhizal fungi (Crossay et al., 2017) and the pathogenic oomycete Pythium insidiosum (Krajaejun et al., 2018).

In this study, we focused on 43 selected strains belonging to 26 Phytophthora species and one species belonging to the genus Pythium as an outgroup. The strain collection was created from isolates acquired from natural as well as anthropogenic (nurseries, gardening centers, fruit orchards, etc.) habitats. The isolates were subjected to genetic identification using the cytochrome c oxidase subunit I (COI) and ITS regions, and the validated strains were grown in liquid medium and subsequently analyzed by MALDI-TOF MS (Figure S1). Finally, a library of 144 main spectra (MSPs) was created and validated.

\section{Materials \& Methods}

\section{Pathogen isolation, cultivation, genetic identification, and preservation}

Oomycetous pathogens were isolated from damaged plants of different ornamental, forest and fruit woody plant species and from water in 2008-2017. Woody plants of many species from different stands (nurseries, orchards, gardening centers and ornamental gardens, forest and riparian stands) with disease symptoms such as yellowing or wilting foliage, dieback, root and collar rot, or rot of feeding roots were identified and examined for the presence of damaged plant tissues. Tissues exhibiting characteristic lesions were aseptically sampled and transported to the laboratory. The samples were rinsed under tap water, and transition zones between necrotized and healthy plant tissues were identified. Segments $(3 \times 3 \mathrm{~mm})$ from the edges of active lesions were excised, surface disinfected by immersion in $95 \%$ ethanol for 10 seconds, rinsed in deionized sterile water and dried with sterile filter paper. Then, the segments were placed on selective PARPNH agar medium (V8 juice $200 \mathrm{~mL}$, ampicillin $200 \mathrm{ppm}$, rifampicin $10 \mathrm{ppm}$, quintozene $25 \mathrm{ppm}$, nystatin $50 \mathrm{ppm}$, hymexazol $50 \mathrm{ppm}$, agar $15 \mathrm{~g}, \mathrm{CaCO}_{3} 3 \mathrm{~g}$, and deionized water $800 \mathrm{~mL}$ ) in $9-\mathrm{cm}$ Petri dishes and incubated at $20^{\circ} \mathrm{C}$ in the dark. After two to five days, segments exhibiting characteristic oomycetous hyphae were transferred onto plates containing V8A medium (V8 juice $200 \mathrm{~mL}$, agar $15 \mathrm{~g}, \mathrm{CaCO}_{3} 3 \mathrm{~g}$, deionized water $800 \mathrm{~mL}$ ). Pure isolates were transferred to oatmeal agar (HiMedia Ltd, India) slants in tubes and stored in refrigeration boxes at $12{ }^{\circ} \mathrm{C}$ in the Czech Collection of Phytopathogenic Oomycetes (CCPO http://www.vukoz.cz/dokumenty/056/Sbirka_Katalog_Jan_2018.pdf).

Samples of soil substrate from plants with damaged feeding roots were collected from three sites at depths of 10-20 cm in the root zone of the affected plants. A mixed sample of approximately $1000-2000 \mathrm{~cm}^{3}$ was then created from a single plant and transported to the laboratory. Soil samples were processed via a baiting method. Approximately $150 \mathrm{~cm}^{3}$ of soil substrate containing damaged roots was placed in a deep plastic bowl, and deionized water was added to cover the sample by $2-3 \mathrm{~cm}$. The bait (young, healthy, rhododendron leaves of the susceptible Rhododendron yakushimanum cv. Silberwolke) was rinsed under tap water, placed on the water surface and incubated at room temperature under natural light in a standard day/night regime. 
120 When characteristic lesions appeared on the baits, the segments with necrotized tissues were

121

122

123

124

125

126

127

128

129

130

131

132

133

134

135

136

137

138

139

140

141

142

143

144

145

146

147

148

149

150

151

152

153

154

155

156

157

158

159 excised and processed as described above. Floating oomycetous zoospores were trapped from water in situ using healthy leaves of $R$. yakushimanum cv. Silberwolke placed in a sterilized bag made from loosely woven fabric. Four bags containing leaf bait were allowed to float just under the surface of the investigated watercourses, and after one week of incubation, the samples were collected, transported to the laboratory and processed as leaf baits as described above.

Total genomic DNA of the isolates was extracted from pure cultures using a DNeasy UltraClean Microbial Kit (QIAGEN, Germany) according to the manufacturer's instructions. For molecular identification, the nuclear rDNA ITS region and/or the COI region were amplified by polymerase chain reaction (PCR). The primer pairs used to amplify the ITS region were ITS1/ITS4 or ITS4/ITS5 (White et al., 1990), and the COI region was amplified with OomCoxILevup/Fm85mod primers (Robideau et al., 2011). PCR was performed in a Mastercycler Nexus Gradient GSX 1 thermal cycler (Eppendorf), and products were visualized via agarose gel electrophoresis in 1\% TBE buffer using a 100-bp DNA ladder (New England Biolabs, US) as a size marker. PCR products were purified and sequenced in both directions by Macrogen Europe B.V. (NL) using the same primers used for PCR amplification. The obtained sequences were edited and aligned in BIOEDIT v. 7.0.9.0 (Hall, 1999) and compared with sequences in GenBank using a BLAST similarity search (www.ncbi.nlm.nih.gov). All sequences obtained in this study were deposited in the NCBI GenBank database (Table S1).

\section{MALDI-TOF MS biotyping}

After genetic identification, cultures of 43 selected strains belonging to 26 taxa of Phytophthora and one species belonging to the genus Pythium as an outgroup were incubated in $0.5 \mathrm{~L}$ of Tryptone Soya Broth (TSB, Sigma Aldrich, USA) with shaking in the dark for 3-7 days (according to the intensity of growth of each species) to develop sufficient mycelial biomass. Samples from the liquid nutrient medium were transferred to $70 \%$ ethanol and stored in Eppendorf tubes at $-20{ }^{\circ} \mathrm{C}$ until analysis. An overview of the species, including their collection numbers, is given in Table S1.

For protein extraction and subsequent MALDI-TOF MS, mycelium was harvested from the liquid nutrient medium samples by centrifugation in a 1.5-mL Eppendorf tube and divided into small, approximately equal-sized pieces of 5-10 mg using micro scissors. Distilled water (300 $\mu \mathrm{L}$ ) was added to each piece of mycelium and mixed thoroughly. Then, $900 \mu \mathrm{L}$ of ethanol was added, followed by thorough mixing. The sample was centrifuged at $20,000 \times \mathrm{g}$ for 2 minutes (Rotanta 450 R, Hettich, DE), the supernatant was decanted, and the sample was briefly centrifuged again. The rest of the supernatant was carefully removed from the pellet by pipetting, and the sample was subsequently allowed to dry at room temperature. Next, $10-20 \mu \mathrm{L}$ of $70 \%$ formic acid (Sigma-Aldrich, DE) was added to fully immerse the dry pellet, followed by thorough mixing and incubation for 3 minutes. Finally, an equal volume of ultrapure acetonitrile (Fluka, DE) was added, followed by thorough mixing and centrifugation at 20,000 $\times \mathrm{g}$ for 2 minutes. One microliter of the supernatant was immediately applied to a spot of an MTP 384 
160

161

162

163

164

165

166

167

168

169

170

171

172

173

174

175

176

177

178

179

180

181

182

183

184

185

186

187

188

189

190

191

192

193

194

195

196

197

198

199

ground steel BC target plate for MALDI-TOF MS (Bruker, DE) and allowed to dry at room temperature. Immediately after drying, $1 \mu 1$ of HCCA ( $\alpha$-cyano-4-hydroxycinnamic acid, Bruker, DE) matrix solution (acetonitrile $50 \%$, water $47.5 \%$ and trifluoracetic acid $2.5 \% ; 10 \mathrm{mg} / \mathrm{mL}$ HCCA) was applied to each spot and allowed to dry again at room temperature. Each sample was applied to 8 spots around the calibration spot. For calibration, $0.5 \mu \mathrm{L}$ of Bruker Bacterial Test Standard (BTS, Bruker, DE) was applied to the center spot, followed by the application of matrix solution as described for the supernatant. Each spot was measured three times by MALDI-TOF MS Autoflex Speed (Bruker, DE) and flexControl 3.4 (Build 135) with a standard MALDI Biotyper method (MBT_FC.par). Ion source 1 was set to $19.38 \mathrm{kV}$, ion source 2 was set to $18.18 \mathrm{kV}$, and detection was set from 2 to $20 \mathrm{kDa}$. All experiments were performed in independent biological triplicates; three spectra were measured for each sample, and each spectrum was collected as 2000 shots in 200 steps.

\section{Data processing}

For each measurement, the spectra were manually inspected by flexAnalysis 3.4 Compass 1.4 (Bruker Daltonics, DE), and then MSPs were processed by the standard MALDI Biotyper MSP creation method using MALDI Biotyper Version 3.1 (Build 66). MALDI Biotyper was used to compare the results based on the similarity of the spectra in the range of 2-20 kDa. For evaluation, the standard method of identification of MSPs was chosen; the frequency threshold for spectrum adjustment was 50 , the frequency threshold for calculating the score was 5 , the maximum primary spectrum mass error was 2000 , the mass tolerance for the modified spectrum was 350 , and the accepted mass tolerance of the peak was 600 par.

The acquired spectrum of the sample was transformed into a peak pattern utilizing dedicated spectral analysis tools. The peak pattern was then compared to reference peak lists of organisms in the reference library, and a $\log$ (score) value between 0.00 and 3.00 was calculated. In brief, identification is based on average peak intensity, peak position and peak occurrence frequency, and each factor is assigned a value between 0 and 1 . The three values are then summed, and the result is normalized to 1000 . The decimal logarithm of the result is taken as the calculated score, such that the maximum achievable score is $3(=\log 1000)$. The values are then classified. The calculated score determines the highest match at the top of the list. The higher the $\log$ (score) value, the higher the degree of similarity to a given organism in the reference library. Values $\geq 2$ indicate high-confidence identifications. $\log$ (score) values between 1.70 and 1.99 need to be confirmed by additional methods. Values below 1.70 indicate that no organism identification is possible (MALDI Biotyper 3.0 User Manual Revision 2, 2011). Data correlations were visualized as score-oriented dendrograms generated from spectra or MSPs in MALDI Biotyper Version 3.1 (Build 66) using the centroid linkage method.

\section{Results}

\section{MSP Library}


200 Over 3500 mass spectra were processed and manually reviewed for quality control to obtain a 201 total of 144 MSPs from 43 different samples; these MSPs were added to a custom MSP library 202 (DOI: 10.5281/zenodo.4271724). The produced MSPs were compared with the available MBT 203 Library BDAL 9.0 (Bruker Daltonics, Germany), which includes 8,468 MSPs, and the MBT 204 Filamentous Fungi Library V1.0 (365 MSPs). After validation and verification of the method, the 205 samples were compared with respect to species and strain classification.

206 Spectra of different Phytophthora strains were searched against the reference Bruker Library, 207 which contains 2,969 species and 8,468 MSPs of various microorganisms, mainly bacteria and 208 fungi, but no Phytophthora strains. None of the sample mass spectra matched the reference 209 organisms, as the obtained identification scores were less than 1.70. The MSPs of the 210 Phytophthora strains were then added to the Bruker MALDI Biotyper Library.

211

212

\section{Library validation and verification}

The same extraction method using ethanol and formic acid was used for validation. Intraday variability was determined based on successful measurement of 8 spots of the same sample in three replicates, and interday variability was based on the similarity of the spectra of samples measured on different days. Each sample was measured at least 3 times. The procedure and conditions were always identical. Figure 1 shows a comparison of the spectra of a sample of Phytophthora lacustris with collection number 295.09. The log scores of identical samples

220 measured on different days are very similar (score $>2.6$ ).

221 Blank analysis was performed to further validate the method. One of the 43 samples was randomly selected and measured in 3 spots by MALDI Biotyper Realtime Classification (Bruker, DE). The sample was correctly identified as P. lacustris in accordance with the previous DNA classification. The spectra of the blank sample matched the MSP in our database as shown in Table 1.

225

\section{From genus to strain using the custom library}

In total, 42 samples within the genus Phytophthora and 1 sample belonging to the related genus

229 Pythium, which was included in the collection for quality control purposes, were compared. The MSP spectra are compared in the form of log score values in Table S2. All 42 samples matched their own MSPs (biological repeats) measured on another day with log scores greater than 2.3. For one sample ( $P$. gonapodyides 419.10 ), the highest match category had a score of 2.3 with only one biological replicate and a second score of 2.2, which is satisfactory for probable species identification. The results of the reliability of identification of all species and strains are summarized in Table 2. Two limit values were determined according to the manufacturer's recommendations. At a limit value of 2 , the confidence of strain identification was $78.3 \%$; at a lower limit value of 1.7 , the success rate was $90.7 \%$.

237

\section{Comparison within a species}


239 The spectra of different strains of $P$. lacustris analyzed in flexAnalysis (Figure 2) showed protein 240 ion peaks in the 6500 and $14500 \mathrm{~m} / \mathrm{z}$ regions for all samples, but the intensities differed among 241 the samples. All spectra were smoothed and baseline aligned prior to evaluation. For P. lacustris, 242 reliable identification of strains from different locations and hosts was also achieved within the 243 species using the log score as shown in Table 3. The MSP dendrogram based on comparison of 244 the MALDI-TOF mass spectra is shown in Figure 3.

245 The MSP spectra of $P$. alni subsp. uniformis 239.08 were very similar to those of $P$. cambivora, 246 P. alni subsp. alni and $P$. rubi. The log scores ranged from 2.4 to 2 , indicating some association among these species. However, the dendrogram placed these species in different clusters (Figure 4). There was also a match of $\log$ scores at the species level between $P$. cactorum 862.17 and $P$. hedraiandra. For the genus Pythium, only consistency among biological replicates was observed. The log score compared to Phytophthora was less than 1.6 (Table 4)

251

\section{Discussion}

253

254

255

256

257

258

259

260

261

262

263

264

265

266

267

268

269

270

271

272

273

274

275

276

277

278

The genera Phytophthora and Pythium include many economically important species that have been placed in Kingdom Chromista (H Ho, 2018). Many Phytophthora species are relatively easy to identify, but overlapping morphological features and intraspecific variability can make genus identification difficult (Martin et al., 2012) in the absence of genetic methods. Cooke et al. (2000) developed the first molecular phylogeny for the genus Phytophthora by analyzing sequences of the ITS region. Several multilocus phylogenies were subsequently constructed that divided Phytophthora species into 10 phylogenetically well-supported clades and several subclades (Kroon et al., 2004; Blair et al., 2008; Martin, Blair \& Coffey, 2014; Yang, Tyler \& Hong, 2017). The clade affiliations of the species used in this study are given in Table S1. After genetic validation using COI and ITS, isolates of these species were grown in liquid medium and subsequently analysed by MALDI-TOF MS to create a database. The MSP database (DOI: $10.5281 /$ zenodo.4271724) created in this study can be used as a complement to existing datasets for fast and reliable identification of Phytophthora.

MALDI-TOF MS is a fast and direct method of analysis that requires no chromatographic separation (Galeano Garcia et al., 2018) and is much less expensive than DNA sequencing (Del Castillo-Múnera et al., 2013). Recent research has demonstrated the usefulness of MALDI-TOF MS for the rapid characterization of clinical pathogens, lactic acid bacteria, nonfermenting bacteria, fungi, plant-parasitic nematodes, and environmental bacteria (Ahmad, Babalola \& Tak, 2012). Moreover, studies using a wide range of microbial species suggest that MALDI-TOF MS has better diagnostic accuracy than conventional biochemical techniques (Ahmad, Babalola \& Tak, 2012). MALDI-TOF MS reference spectra and analytical tools are usually proprietary, in contrast to the wide range of public repositories of openly accessible or downloadable data and tools for DNA-based identification. For example, in 2012, Bruker Daltonics launched Filamentous Fungi Library 1.0, a commercial MS library for fungal identification (Schulthess et al., 2014). The production and integration of in-house MS databases for open access would facilitate the creation of a truly open platform for MALDI-TOF MS-based species identification

Peer) reviewing PDF | (2021:03:59163:1:1:NEW 28 May 2021) 
279 (Drissner \& Freimoser, 2017) and promote the use of MALDI-TOF MS biotyping in other areas 280 of diagnostics, such as plant pathogens or food-important bacteria, fungi and yeasts (Drissner \& 281 Freimoser, 2017).

282 Most studies using MALDI-TOF MS for microbial identification refer to the Bruker system, 283 which is proprietary but the most widespread system (Normand et al., 2017). Studies of the 284 identification of filamentous fungal species using the Bruker system have focused on the genera 285 Fusarium, Aspergillus, Penicillium and Ramularia, which are potentially dangerous to humans 286 (Boekhout et al., 2015). However, analyses of dermatophyte genera using the Saramis, Vitek MS 287 or Andromas systems have also been published. In human clinical microbiology, MALDI-TOF 288 MS has primarily been used for the identification of bacteria and yeasts using in-house MS 289 databases of human pathogens (Gräser, 2014; Lasch, Stämmler \& Schneider, 2018; Paul et al., 290 2019; Papalia et al., 2020) and environmental isolates of Burkholderia and related genera 291 (Fergusson et al., 2020).

292 Although MALDI-TOF MS is becoming increasingly popular as a tool for clinical diagnosis, the 293 lack of data on non-clinical microorganisms has limited its use in microbial ecology (Rahi, 294 Prakash \& Shouche, 2016). So far very little attention has been paid to plant pathogens such as 295 Phytophthora. Even organisms commonly found in environmental, agricultural, or food samples 296 are often not recognized by standard, commercial MALDI-TOF MS systems (Drissner \& 297 Freimoser, 2017). The available MBT Library BDAL 9.0 (Bruker Daltonics, Germany), which 298 includes 8,468 MSPs, and the MBT Filamentous Fungi Library V1.0 (365 MSPs) do not contain 299 any representatives of the genus Phytophthora. In a previous study, an in-house MS database 300 was used to accurately identify Pythium insidiosum isolates and properly differentiate them from 301 other filamentous fungi in patient samples (Mani et al., 2019), thus demonstrating that MALDITOF MS can be used for the accurate and rapid culture identification of Pythium insidiosum in

304

305

306

307

308

309

310

311

312

313

314

315

316

317

318 the clinical laboratory. Our dataset contained Pythium folliculosum as a control strain that can be reliably distinguished from other Phytophthora species. As a contrast to this technical approach, ongoing studies suggesting that dogs can also rapidly and reliably distinguish plants infected with Phytophthora or Pythium species (Swiecki et al., 2018; Oliver et al., 2020).

The MSP spectra of $P$. hedraiandra and $P$. cactorum were similar, consistent with phylogenetic studies that have indicated that $P$. hedraiandra is closely related to $P$. cactorum or basal to the cluster of P. cactorum and P. pseudotsugae (Blair et al., 2008; Martin, Blair \& Coffey, 2014; Yang, Tyler \& Hong, 2017); all of these species belong to Subclade 1a. Similarity of the MSP spectra was also observed for $P$. alni subsp. alni, $P$. alni subsp. uniformis, $P$. cambivora and $P$. rubi, which are phylogenetically closely related and belong to Subclade 7a (Yang, Tyler \& Hong, 2017). Despite these similarities, we were able to discriminate 43 genetically and phenotypically distinct Phytophthora strains by native Bruker Biotyper methods.

Some in house databases based on profile mass spectra was developed for identification of species of Xanthomonas (Sindt et al., 2018). Rhizopus (Boekhout et al., 2015), Tuber (El Karkouri et al., 2019). MALDI-TOF MS has also been used for the in situ identification of plantinvasive bacteria, including rhizobia (Ziegler et al., 2012) and Acidovorax citrulli isolates 
319 (Bergsma-Vlami, 2018) and late blight in asymptomatic tomato plants (Galeano Garcia et al., 320 2018).

321 MALDI-TOF MS-based identification of $P$. insidiosum revealed differences in protein spectra 322 between geographically different isolates (Mani et al., 2019). While our samples were also taken

323 from geographically different habitats and hosts, the results clearly showed that these differences 324 did not affect the reliability of identification. Notably, we were able to use our constructed 325 database to distinguish $P$. palmivora and $P$. infestans with high reliability. Previous protein 326 profiling of these two species by two-dimensional gel electrophoresis showed that the overall

327

328

329

330

331

332

333

334

335

336

337

338

339

340

341

342

343

344

345

346

347

348

349

350

351

352

353

354

355

356

357

358

359 proteome maps were similar; equivalent numbers of spots were detected for the two species, and $30 \%$ of the protein spots had similar or identical positions in the 2D gels (Shepherd, Van West \& Gow, 2003). Thus, our results suggest that the use of MALDI-TOF MS biotyping combined with simple sample processing and subsequent comparison of spectra with a database is effective for the accurate and rapid identification of Phytophthora genera and species. In addition, due to its simplicity, this method could be useful for laboratories with limited expertise in mycology (Mani et al., 2019).

\section{Conclusions}

This study demonstrated that MALDI-TOF MS can be used to identify phytopathogens of the genus Phytophthora. None of the Phytophthora isolates have previously been included in a commercial library. Our updated library allowed the correct identification of 117/129 (90.6\%) Phytophthora isolates at the species level and $100 \%$ of isolates at the genus level. The success rate within species was $78.3 \%$ at a cut-off value of 2 and $90.7 \%$ at the lower limit of 1.7 . In addition, protein extraction using ethanol, formic acid and acetonitrile was quick and effective. Further development of MALDI-TOF MS-based identification of fibrous oomycetes will require continuous updating of current commercial databases and devices as well as the construction of new databases for specialized research purposes. Another prospect for development is the potential detection of typical MS markers of Phytophthora species directly in infected plant material.

\section{Acknowledgements}

The authors wish to thank Dawn Schmidt for language editing.

\section{References}

Ahmad F, Babalola OO, Tak HI. 2012. Potential of MALDI-TOF mass spectrometry as a rapid detection technique in plant pathology: identification of plant-associated microorganisms. Analytical and Bioanalytical Chemistry 404:1247-1255. DOI: 10.1007/s00216-012-6091-7.

De Bary A. 1876. Researches into the nature of the potato fungus, Phytophthora infestans. Journal of the Royal Agricultural Society of England 12:239-269.

Bergsma-Vlami M. 2018. MALDI-TOF mass spectrometry for plant pest diagnostics: the case of the accurate identification of Acidovorax citrulli isolates, including their grouping. DOI: 10.5281/ZENODO.1168430. 
360

361

362

363

364

365

366

367

368

369

370

371

372

373

374

375

376

377

378

379

380

381

382

383

384

385

386

387

388

389

390

391

392

393

394

395

396

397

398

399

400

401

402

403

404

405

Blair JE, Coffey MD, Park SY, Geiser DM, Kang S. 2008. A multi-locus phylogeny for Phytophthora utilizing markers derived from complete genome sequences. Fungal Genetics and Biology 45. DOI: 10.1016/j.fgb.2007.10.010.

Boekhout T, Versteeg M, Dolatabadi S, de Hoog SG, Kolecka A. 2015. Differentiation of clinically relevant Mucorales Rhizopus microsporus and R. arrhizus by matrix-assisted laser desorption ionization time-of-flight mass spectrometry (MALDI-TOF MS). Journal of Medical Microbiology 64:694-701. DOI: 10.1099/jmm.0.000091.

Brasier CM. 2009. Phytophthora biodiversity: How many Phytophthora species are there? In: Phytophthoras in Forests and Natural Ecosystems. (Goheen EM and Frankel SJ, eds). Proceedings of the Fourth International Union of Forest Research Organisations (IUFRO) Working Party 7.02.09. USDA Forest Service General Technical Report, 101-115.

Del Castillo-Múnera J, Cárdenas M, Pinzón A, Castañeda A, Bernal AJ, Restrepo S. 2013. Developing a taxonomic identification system of Phytophthora species based on microsatellites. Revista Iberoamericana de Micologia. DOI: 10.1016/j.riam.2012.11.002.

Cooke DEL, Drenth A, Duncan JM, Wagels G, Brasier CM. 2000. A molecular phylogeny of phytophthora and related oomycetes. Fungal Genetics and Biology 30. DOI: 10.1006/fgbi.2000.1202.

Crossay T, Antheaume C, Redecker D, Bon L, Chedri N, Richert C, Guentas L, Cavaloc Y, Amir H. 2017. New method for the identification of arbuscular mycorrhizal fungi by proteomicbased biotyping of spores using MALDI-TOF-MS. Scientific Reports 7:14306. DOI: 10.1038/s41598-017-14487-6.

Drissner D, Freimoser FM. 2017. MALDI-TOF mass spectroscopy of yeasts and filamentous fungi for research and diagnostics in the agricultural value chain. Chemical and Biological Technologies in Agriculture 4:13. DOI: 10.1186/s40538-017-0095-7.

Erwin DC, Ribeiro OK. 1996. Phytophthora diseases worldwide. American Phytopathological Society, St. Paul, MN (USA) APS Press.

Fergusson CH, Coloma JMF, Valentine MC, Haeckl FPJ, Linington RG. 2020. Custom matrixassisted laser desorption ionization-time of flight mass spectrometric database for identification of environmental isolates of the genus burkholderia and related genera. Applied and Environmental Microbiology 86:778-782. DOI: 10.1128/AEM.00354-20.

Galeano Garcia P, Neves dos Santos F, Zanotta S, Eberlin M, Carazzone C. 2018. Metabolomics of Solanum lycopersicum Infected with Phytophthora infestans Leads to Early Detection of Late Blight in Asymptomatic Plants. Molecules 23:3330. DOI: $10.3390 /$ molecules 23123330 .

Gräser Y. 2014. Species Identification of Dermatophytes by MALDI-TOF MS. Current Fungal Infection Reports 8:193-197. DOI: 10.1007/s12281-014-0189-7.

Greslebin AG, Hansen EM, Sutton W. 2007. Phytophthora austrocedrae sp. nov., a new species associated with Austrocedrus chilensis mortality in Patagonia (Argentina). Mycological Research 111:308-316. DOI: 10.1016/j.mycres.2007.01.008.

Grünwald NJ, Martin FN, Larsen MM, Sullivan CM, Press CM, Coffey MD, Hansen EM, Parke JL. 2011. Phytophthora-ID.org: A sequence-based phytophthora identification tool. Plant Disease 95. DOI: 10.1094/PDIS-08-10-0609.

H Ho H. 2018. The Taxonomy and Biology of Phytophthora and Pythium. Journal of Bacteriology \& Mycology: Open Access 6. DOI: 10.15406/jbmoa.2018.06.00174.

Hansen EM, Reeser PW, Sutton W. 2012. Phytophthora Beyond Agriculture. Annual Review of Phytopathology 50:359-378. DOI: 10.1146/annurev-phyto-081211-172946.

Peer) reviewing PDF | (2021:03:59163:1:1:NEW 28 May 2021) 
406

407

408

409

410

411

412

413

414

415

416

417

418

419

420

421

422

423

424

425

426

427

428

429

430

431

432

433

434

435

436

437

438

439

440

441

442

443

444

445

446

447

448

449

450

451
Hardham AR, Blackman LM. 2018. Phytophthora cinnamomi. Molecular Plant Pathology 19:260-285. DOI: 10.1111/mpp.12568.

Husson C, Aguayo J, Revellin C, Frey P, Ioos R, Marçais B. 2015. Evidence for homoploid speciation in Phytophthora alni supports taxonomic reclassification in this species complex. Fungal Genetics and Biology 77:12-21. DOI: 10.1016/j.fgb.2015.02.013.

Jung T, La Spada F, Pane A, Aloi F, Evoli M, Horta Jung M, Scanu B, Faedda R, Rizza C, Puglisi I, Magnano di San Lio G, Schena L, Cacciola SO. 2019. Diversity and Distribution of Phytophthora Species in Protected Natural Areas in Sicily. Forests 10:259. DOI: 10.3390/f10030259.

El Karkouri K, Couderc C, Decloquement P, Abeille A, Raoult D. 2019. Rapid MALDI-TOF MS identification of commercial truffles. Scientific Reports 9:17686. DOI: 10.1038/s41598019-54214-X.

Krajaejun T, Lohnoo T, Jittorntam P, Srimongkol A, Kumsang Y, Yingyong W, Rujirawat T, Reamtong O, Mangmee S. 2018. Assessment of matrix-assisted laser desorption ionizationtime of flight mass spectrometry for identification and biotyping of the pathogenic oomycete Pythium insidiosum. International Journal of Infectious Diseases 77:61-67. DOI: 10.1016/j.ijid.2018.09.006.

Kroon LPNM, Bakker FT, Van Den Bosch GBM, Bonants PJM, Flier WG. 2004. Phylogenetic analysis of Phytophthora species based on mitochondrial and nuclear DNA sequences. Fungal Genetics and Biology 41. DOI: 10.1016/j.fgb.2004.03.007.

Lasch P, Stämmler M, Schneider A. 2018. Version 3 (20181130) of the MALDI-TOF Mass Spectrometry Database for Identification and Classification of Highly Pathogenic Microorganisms from the Robert Koch-Institute (RKI). DOI: 10.5281/ZENODO.1880975.

Mani R, Vilela R, Kettler N, Chilvers MI, Mendoza L. 2019. Identification of Pythium insidiosum complex by matrix-assisted laser desorption ionization-time of flight mass spectrometry. Journal of Medical Microbiology 68:574-584. DOI: 10.1099/jmm.0.000941.

Martin FN, Abad ZG, Balci Y, Ivors K. 2012. Identification and Detection of Phytophthora: Reviewing Our Progress, Identifying Our Needs. Plant Disease 96:1080-1103. DOI: 10.1094/PDIS-12-11-1036-FE.

Martin FN, Blair JE, Coffey MD. 2014. A combined mitochondrial and nuclear multilocus phylogeny of the genus Phytophthora. Fungal Genetics and Biology 66. DOI: 10.1016/j.fgb.2014.02.006.

Martin FN, Tooley PW. 2003. Phylogenetic relationships among Phytophthora species inferred from sequence analysis of mitochondrially encoded cytochrome oxidase I and II genes. Mycologia 95. DOI: 10.1080/15572536.2004.11833112.

Mizeriene G, Cerny K, Zyka V, Bakonyi J, Nagy ZÁ, Oliva J, Redondo MA, Corcobado T, Martín-García J, Prospero S. 2020. Patterns of Genetic Diversification in the Invasive Hybrid Plant Pathogen Phytophthora $\times$ alni and Its Parental Species P. uniformis. Phytopathology ${ }^{\circledR}$ 110:1959-1969. DOI: 10.1094/PHYTO-12-19-0475-R.

Normand A-C, Cassagne C, Gautier M, Becker P, Ranque S, Hendrickx M, Piarroux R. 2017. Decision criteria for MALDI-TOF MS-based identification of filamentous fungi using commercial and in-house reference databases. BMC Microbiology 17:25. DOI:

10.1186/s12866-017-0937-2.

Oliver L, Quinn M, Popenuck T, Garbelotto M. 2020. Phytophthora species Can Be Reliably Detected by Dogs Both From Infested Substrates and Infected Plants 1.

Papalia M, Figueroa-Espinosa R, Steffanowski C, Barberis C, Almuzara M, Barrios R, Vay C, 
452

453

454

455

456

457

458

459

460

461

462

463

464

465

466

467

468

469

470

471

472

473

474

475

476

477

478

479

480

481

482

483

484

485

486

487

488

489

490

491

492

493

494

495

496

497

Gutkind G, Di Conza J, Radice M. 2020. Expansion and improvement of MALDI-TOF MS databases for accurate identification of Achromobacter species. Journal of Microbiological Methods 172:105889. DOI: 10.1016/j.mimet.2020.105889.

Park J, Park B, Veeraraghavan N, Jung K, Lee Y-H, Blair JE, Geiser DM, Isard S, Mansfield MA, Nikolaeva E, Park S-Y, Russo J, Kim SH, Greene M, Ivors KL, Balci Y, Peiman M, Erwin DC, Coffey MD, Rossman A, Farr D, Cline E, Grünwald NJ, Luster DG, Schrandt J, Martin F, Ribeiro OK, Makalowska I, Kang S. 2008. Phytophthora Database: A Forensic Database Supporting the Identification and Monitoring of Phytophthora. Plant Disease 92:966-972. DOI: 10.1094/PDIS-92-6-0966.

Paul S, Singh P, Sharma S, Prasad GS, Rudramurthy SM, Chakrabarti A, Ghosh AK. 2019. MALDI-TOF MS-Based Identification of Melanized Fungi is Faster and Reliable After the Expansion of In-House Database. PROTEOMICS - Clinical Applications 13:1800070. DOI: 10.1002/prca.201800070.

Prigigallo MI, Abdelfattah A, Cacciola SO, Faedda R, Sanzani SM, Cooke DEL, Schena L. 2016. Metabarcoding Analysis of Phytophthora Diversity Using Genus-Specific Primers and 454 Pyrosequencing. Phytopathology 106:305-313. DOI: 10.1094/PHYTO-07-150167-R.

Rahi P, Prakash O, Shouche YS. 2016. Matrix-assisted laser desorption/ionization time-of-flight mass-spectrometry (MALDI-TOF MS) based microbial identifications: Challenges and scopes for microbial ecologists. Frontiers in Microbiology 7:1359. DOI: 10.3389/fmicb.2016.01359.

Ristaino JB. 2012. A Lucid Key to the Common Species of Phytophthora. Plant Disease 96:897-903. DOI: 10.1094/PDIS-08-11-0636.

Rizzato C, Lombardi L, Zoppo M, Lupetti A, Tavanti A. 2015. Pushing the Limits of MALDITOF Mass Spectrometry: Beyond Fungal Species Identification. Journal of Fungi 1:367383. DOI: $10.3390 /$ jof1030367.

Robideau GP, De Cock AWAM, Coffey MD, Voglmayr H, Brouwer H, Bala K, Chitty DW, Désaulniers N, Eggertson QA, Gachon CMM, Hu C-H, Küpper FC, Rintoul T 1., Sarhan E, Verstappen ECP, Zhang Y, Bonants PJM, Ristaino JB, André Lévesque C. 2011. DNA barcoding of oomycetes with cytochrome c oxidase subunit I and internal transcribed spacer. Molecular Ecology Resources 11:1002-1011. DOI: 10.1111/j.17550998.2011.03041.x.

Ruiz Gómez FJ, Navarro-Cerrillo RM, Pérez-de-Luque A, Oßwald W, Vannini A, MoralesRodríguez C. 2019. Assessment of functional and structural changes of soil fungal and oomycete communities in holm oak declined dehesas through metabarcoding analysis. Scientific Reports. DOI: 10.1038/s41598-019-41804-y.

Sandoval-Sierra JV, Martín MP, Diéguez-Uribeondo J. 2014. Species identification in the genus $<\mathrm{i}>$ Saprolegnia $</ \mathrm{i}>$ (Oomycetes): Defining DNA-based molecular operational taxonomic units. Fungal Biology 118:559-578. DOI: 10.1016/j.funbio.2013.10.005.

Schulthess B, Ledermann R, Mouttet F, Zbinden A, Bloemberg G V., Böttger EC, Hombach M. 2014. Use of the Bruker MALDI Biotyper for identification of molds in the clinical mycology laboratory. Journal of Clinical Microbiology 52:2797-2803. DOI: 10.1128/JCM.00049-14.

Shepherd SJ, Van West P, Gow NAR. 2003. Proteomic analysis of asexual development of Phytophthora palmivora. Mycological Research 107:395-400. DOI: 10.1017/S0953756203007561. 
498

499

500

501

502

503

504

505

506

507

508

509

510

511

512

513

514

515

516

517

Sindt NM, Robison F, Brick MA, Schwartz HF, Heuberger AL, Prenni JE. 2018. MALDI-TOFMS with PLS Modeling Enables Strain Typing of the Bacterial Plant Pathogen Xanthomonas axonopodis. Journal of the American Society for Mass Spectrometry 29:413421. DOI: $10.1007 / \mathrm{s} 13361-017-1839-0$.

Sugawara R, Yamada S, Tu Z, Sugawara A, Suzuki K, Hoshiba T, Eisaka S, Yamaguchi A. 2016. Rapid and reliable species identification of wild mushrooms by matrix assisted laser desorption/ionization time of flight mass spectrometry (MALDI-TOF MS). Analytica Chimica Acta 934:163-169. DOI: 10.1016/j.aca.2016.05.056.

Swiecki TJ, Quinn M, Sims L, Bernhardt E, Oliver L, Popenuck T, Garbelotto M. 2018. Three new Phytophthora detection methods, including training dogs to sniff out the pathogen, prove reliable. California Agriculture. DOI: 10.3733/ca.2018a0026.

White TJ, Bruns T, Lee S, Taylor J. 1990. Amplification and direct sequencing of fungal ribosomal rna genes for phylogenetics. In: PCR Protocols. DOI: 10.1016/b978-0-12372180-8.50042-1.

Yang X, Tyler BM, Hong C. 2017. An expanded phylogeny for the genus Phytophthora. IMA Fungus 8. DOI: 10.5598/imafungus.2017.08.02.09.

Ziegler D, Mariotti A, Pflüger V, Saad M, Vogel G, Tonolla M, Perret X. 2012. In Situ Identification of Plant-Invasive Bacteria with MALDI-TOF Mass Spectrometry. PLoS ONE 7:e37189. DOI: 10.1371/journal.pone.0037189. 
Figure 1

Comparison of the interday variability of spectra of $P$. lacustris 295.09

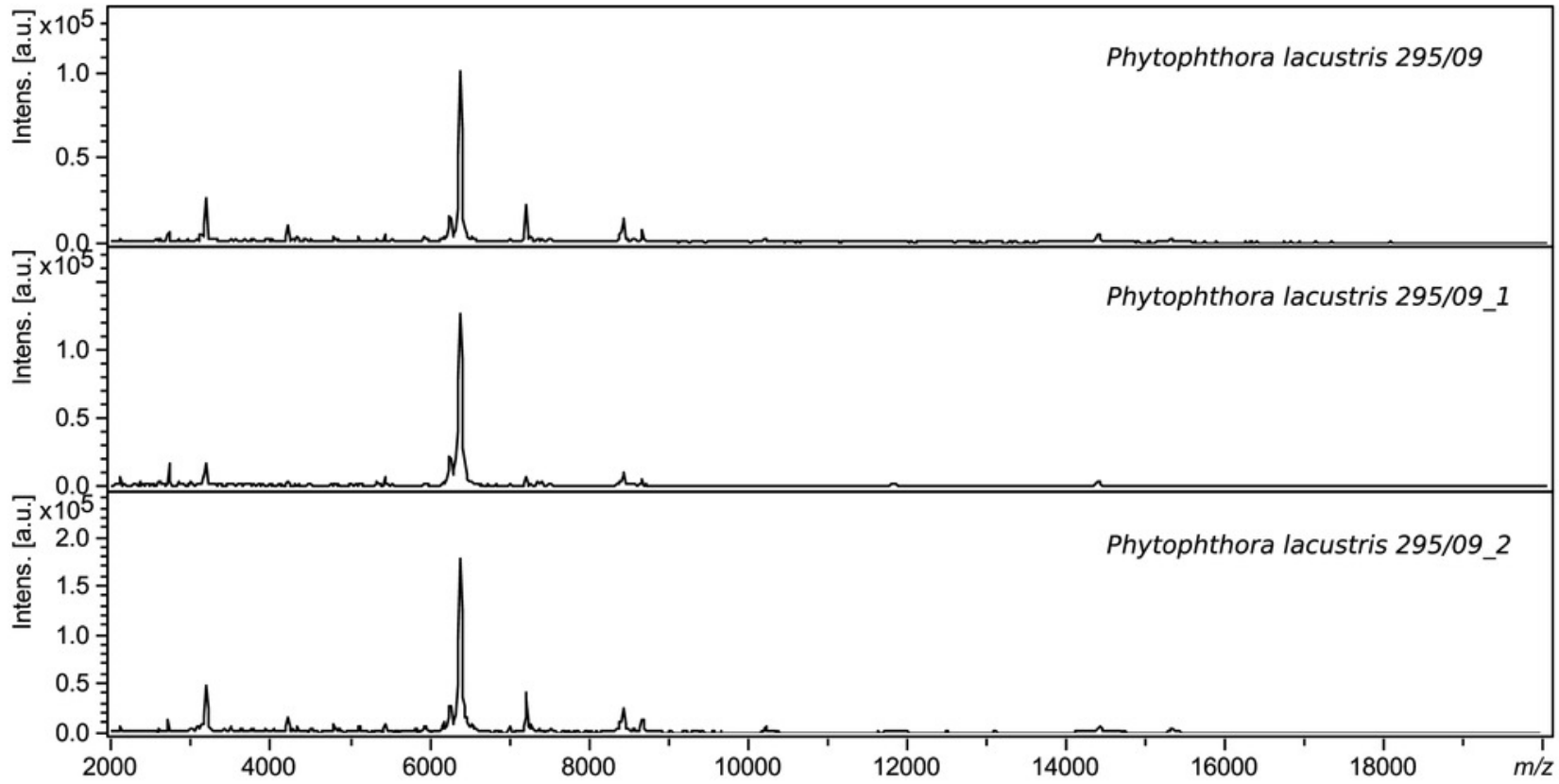


Figure 2

Protein spectra of different strains of $P$. lacustris

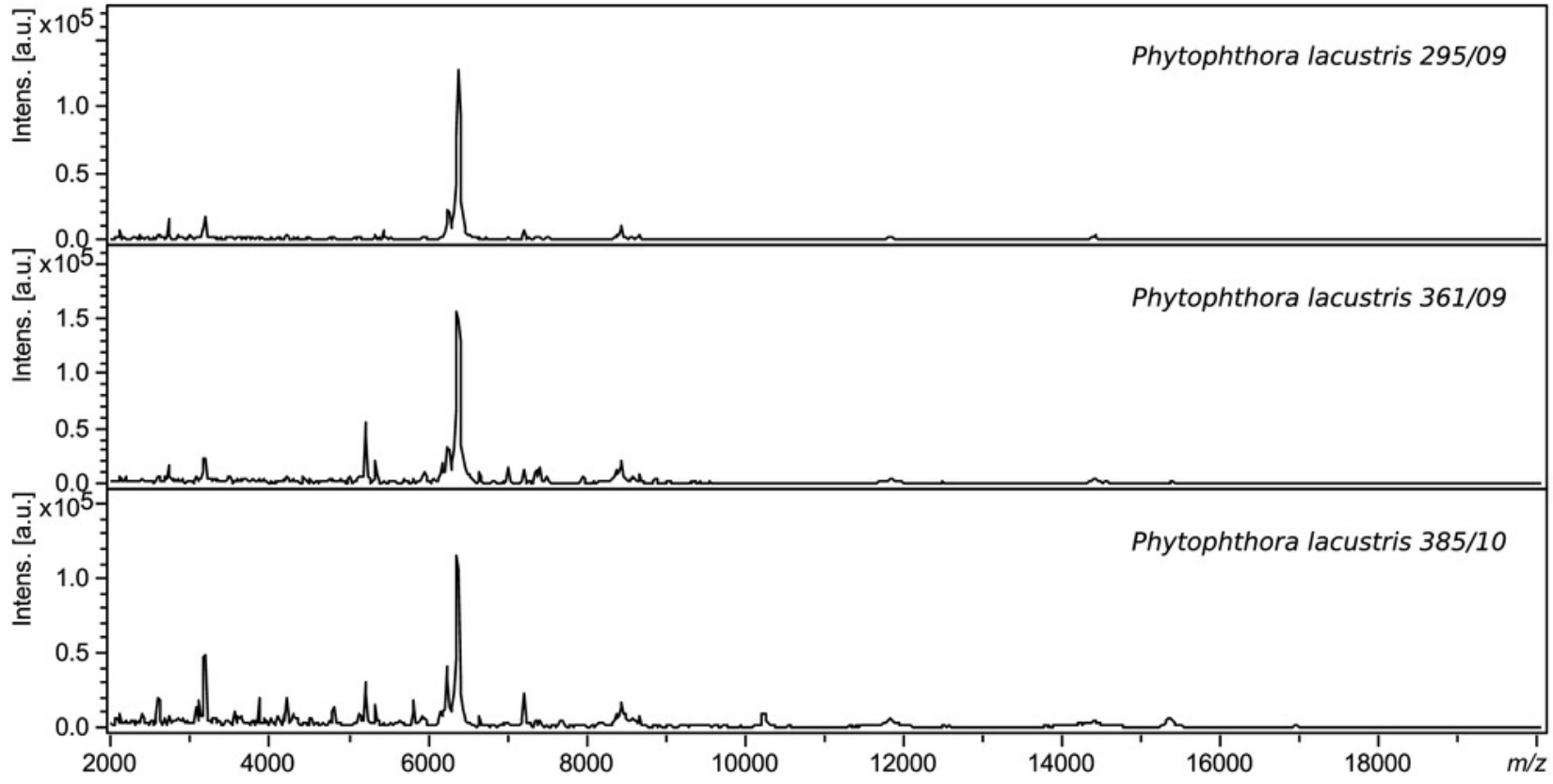


Figure 3

\section{MSP dendrogram of $P$. lacustris from different locations}

MSP Dendrogram of $P$. lacustris from different locations

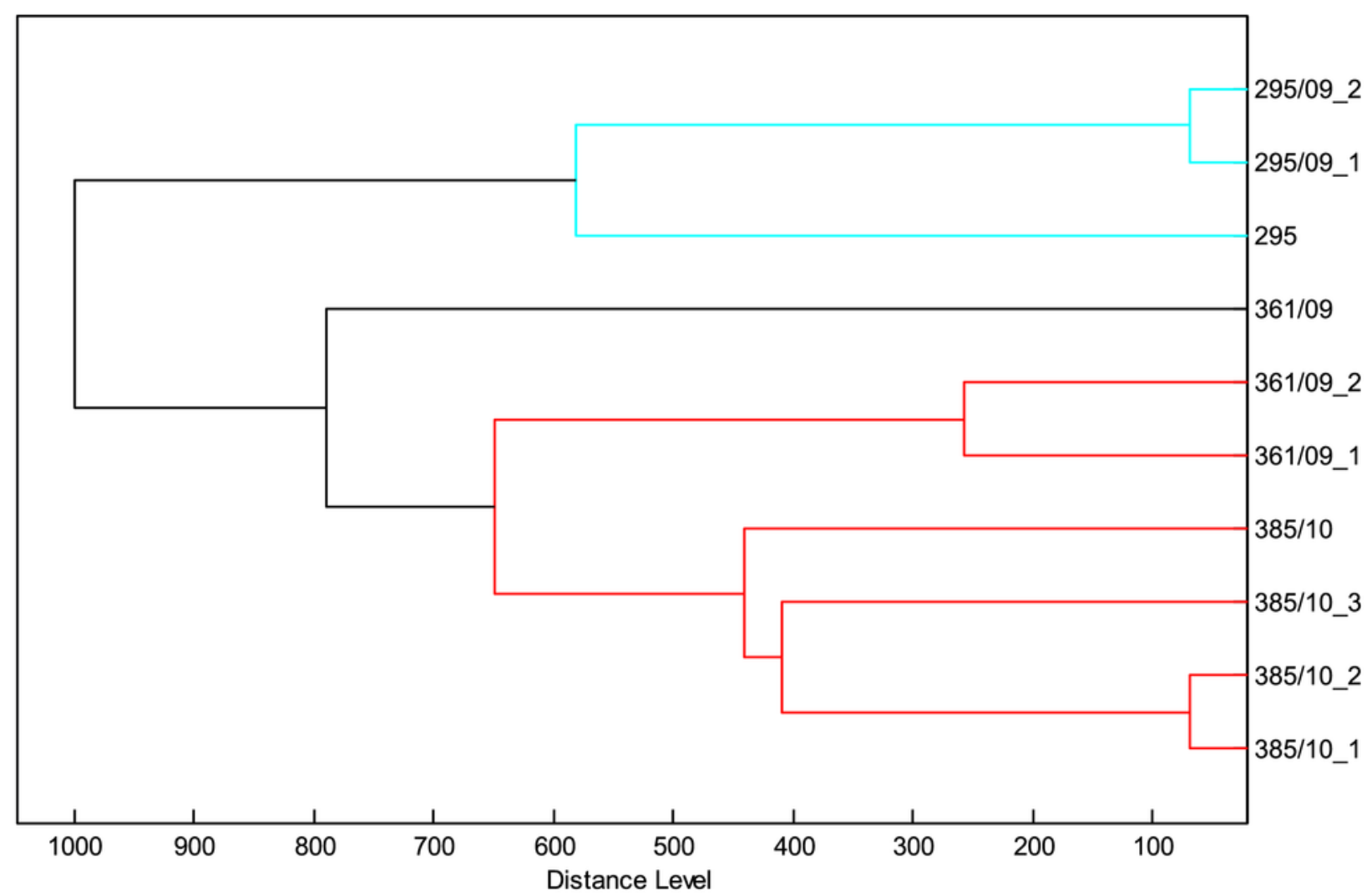


Figure 4

Distribution of different species with similar spectral profiles according to MSP dendrogram cluster analysis

MSP Dendrogram of different Phytophthora species

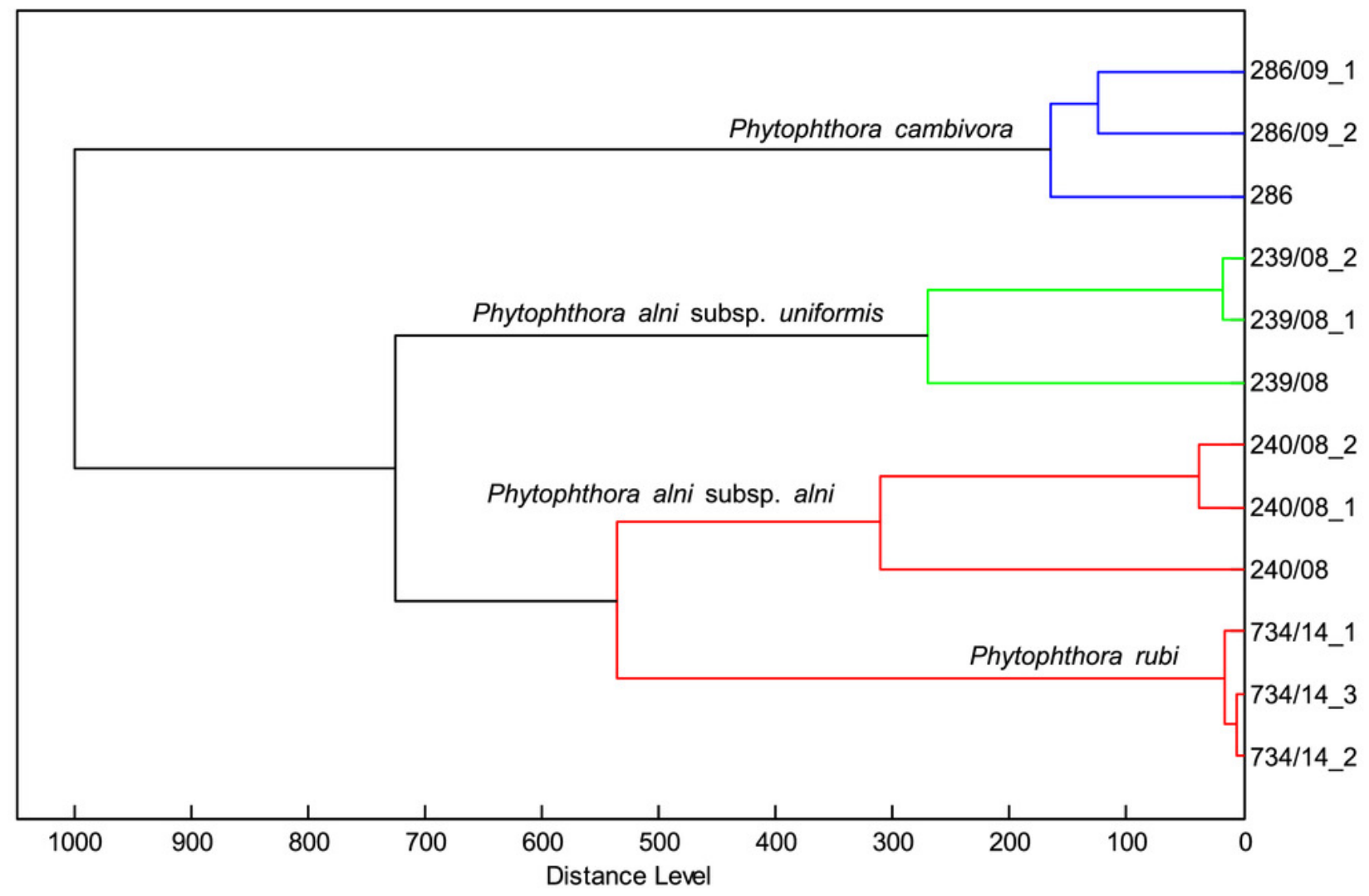




\section{Table 1 (on next page)}

Evaluation of rapid blank sample identification 
1 Table 1 Evaluation of rapid blank sample identification

\begin{tabular}{|c|c|c|c|c|c|}
\hline Repletion & ID & Best match & Score & Second match & Score \\
\hline 1 & Blank & $\begin{array}{l}\text { Phytophthora lacustris } \\
398.10 / 2\end{array}$ & 2.686 & $\begin{array}{l}\text { Phytophthora lacustris } \\
398.10 / 1\end{array}$ & 2.624 \\
\hline 2 & Blank & $\begin{array}{l}\text { Phytophthora lacustris } \\
398.10 / 2\end{array}$ & 2.725 & $\begin{array}{l}\text { Phytophthora lacustris } \\
398.10 / 1\end{array}$ & 2.688 \\
\hline 3 & Blank & $\begin{array}{l}\text { Phytophthora lacustris } \\
398.10 / 2\end{array}$ & 2.718 & $\begin{array}{l}\text { Phytophthora lacustris } \\
398.10 / 1\end{array}$ & 2.697 \\
\hline
\end{tabular}

2 
Table 2 (on next page)

Numbers of correctly identified species and strains with different score values 
1 Table 2 Identification of $P$. lacustris from different locations and hosts

\begin{tabular}{llllll}
\hline Strain & \multicolumn{5}{l}{ Database match* } \\
P. lacustris 361.09 & $361.09 / 2$ & $385.10 / 2$ & $295.09 / 1$ & 385.10 & $295.09 / 2$ \\
score & 2.796 & 2.668 & 2.593 & 2.589 & 2.464 \\
P. lacustris 295.09 & $295.09 / 2$ & $361.09 / 2$ & $361.09 / 1$ & 295.09 & 361.09 \\
score & 2.759 & 2.64 & 2.591 & 2.536 & 2.362 \\
P. lacustris 385.10 & $385.10 / 2$ & 385.10 & $361.09 / 1$ & $385.10 / 3$ & $361.09 / 2$ \\
score & 2.749 & 2.599 & 2.586 & 2.578 & 2.445 \\
\hline
\end{tabular}

* The number after the slash indicates the number of biological replicates. 


\section{Table 3 (on next page)}

Identification of P.lacustris from different locations and hosts 
1 Table 3 Identification of $P$. lacustris from different locations and hosts

\begin{tabular}{|c|c|c|c|c|c|}
\hline Strain & Database & tch* & & & \\
\hline P. lacustris 361.09 & $361.09 / 2$ & $385.10 / 2$ & 295.09/1 & 385.10 & $295.09 / 2$ \\
\hline score & 2.796 & 2.668 & 2.593 & 2.589 & 2.464 \\
\hline P. lacustris 295.09 & $295.09 / 2$ & $361.09 / 2$ & $361.09 / 1$ & 295.09 & 361.09 \\
\hline score & 2.759 & 2.64 & 2.591 & 2.536 & 2.362 \\
\hline P. lacustris 385.10 & $385.10 / 2$ & 385.10 & $361.09 / 1$ & $385.10 / 3$ & $361.09 / 2$ \\
\hline score & 2.749 & 2.599 & 2.586 & 2.578 & 2.445 \\
\hline
\end{tabular}

2 
Table 4 (on next page)

Pythium vs Phytophthora 
1 Table 4 Evaluation of rapid blank sample identification

\begin{tabular}{|c|c|c|c|c|c|}
\hline Repletion & ID & Best match & Score & Second match & Score \\
\hline 1 & Blank & $\begin{array}{l}\text { Phytophthora lacustris } \\
398.10 / 2\end{array}$ & 2.686 & $\begin{array}{l}\text { Phytophthora lacustris } \\
398.10 / 1\end{array}$ & 2.624 \\
\hline 2 & Blank & $\begin{array}{l}\text { Phytophthora lacustris } \\
398.10 / 2\end{array}$ & 2.725 & $\begin{array}{l}\text { Phytophthora lacustris } \\
398.10 / 1\end{array}$ & 2.688 \\
\hline 3 & Blank & $\begin{array}{l}\text { Phytophthora lacustris } \\
398.10 / 2\end{array}$ & 2.718 & $\begin{array}{l}\text { Phytophthora lacustris } \\
398.10 / 1\end{array}$ & 2.697 \\
\hline
\end{tabular}

2 